\title{
The assessment of the technical condition of SO-3 engine turbine blades using an impulse test
}

The paper presents the effects of the application of an experimental impulse test as a method of diagnosis of the technical condition of an SO-3 engine turbine blade fitted in a TS-11 Iskra aircraft. The aim of the test was to investigate the frequency characteristics of the blades and discuss differences between the frequency spectrum of the investigated component before and after its damage. The acoustic response measurements were performed to the signal generated by an impact hammer on the fully functional and intentionally damaged blades. The recorded signals were converted from the domain of time to the domain of frequency using the Fast Fourier Transform (FFT). The results of the FFT were the Frequency Response Functions (FRF) of the sound of the blades, based on which the statistical analysis of the resonance frequencies was carried out. The influence of the mechanical damage of the blade on the shape and characteristics of the frequency spectrum was confirmed, which substantiated the effectiveness of the impulse test in the diagnostic assessment of jet engine components.

Key words: jet engine, turbine, modal analysis, resonance

\section{Introduction}

Turbine as the fundamental component of a jet engine is a rotor flow machine, converting the enthalpy of the working medium to mechanical work subsequently taken off by the compressor and other engine aggregates [4]. Reducing the turbine efficiency results in a reduction of the engine thrust and increased unit fuel consumption. Therefore, its high durability and operational reliability are required, both directly depending on the geometry of the turbine subcomponents constantly subject to thermal and mechanical loads. The unwanted consequences of these loads are not always easy to identify [5] and the blades operating under severe conditions (resonance vibration) are prone to damage in a short time. Material fatigue and turbine blade deformation, apart from reducing the engine efficiency, may lead to its malfunction and, as a consequence, an air disaster [7, 13].

Among the vibroacoustic methods of diagnosing the jet engine rotors we may distinguish, in particular, the vibration spectrum analysis as well as investigations of the mo dal properties. The first method consists in determining the discrete components of frequencies that are compared with the characteristic frequencies, resulting from the design of the engine and its operating conditions at a given speed. The other method is based on precise measurement of the object vibration, through an electrodynamic exciter or, mechanically, with an impact hammer and allows determining the relation between the geometry of the turbine and its technical condition. In both cases, thanks to the application of the Fast Fourier Transform (FFT) we may switch from the function of time, in which the measurements are made, to the function of frequency, which aside from the general assessment of the condition of the component, also allows identification of the sources of the malfunction [8].

The aim of the investigations was the determination of the frequency signature of selected turbine blades (SO-3 jet engine) as well as the assessment of the effectiveness of the impulse test in comparing the damaged blades with the undamaged ones. In order to obtain the expected results, the measurements were preliminarily performed on 11 undam- aged blades and then certain modifications were imposed on two of them. The intentional damage locally modified the rigidity of the component and resulted in changing the parameters of the modal model, significantly influencing the components of the vibration spectrum and the resonance characteristics. On this basis, the authors determined the general areas and characteristics of the spectrum denoting the structural flaws.

\section{Methodology}

\subsection{The object of investigations}

The SO-3 jet engine, from which the turbine components were taken for the investigations, was manufactured specifically for the PZL TS-11 Iskra training aircraft by Polskie Zakłady Lotnicze in Mielec. The turbine is a single stage, axial flow reactive one with a constant outer and inner channel diameter. The diameter of the rotor disc holding 83 blades with groove locks is $760 \mathrm{~mm} \mathrm{[10].} \mathrm{The} \mathrm{aero-}$ foil part of a single blade is $64 \mathrm{~mm}$ long and the chord of its profile $-28 \mathrm{~mm}$. The blade is made from a refractory alloy of steel and nickel and weighs 73 grams. An undamaged blade has been shown in Fig. 1a, while Figs. 1b and 1c present the intentionally damaged structures simulating failure in operation such as overheating or excess torsionalflexural vibration leading to material fatigue $[1,13]$. a)

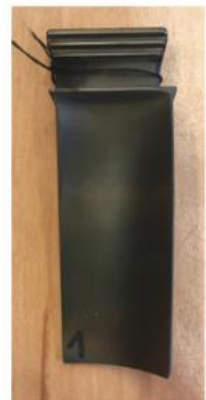

b)

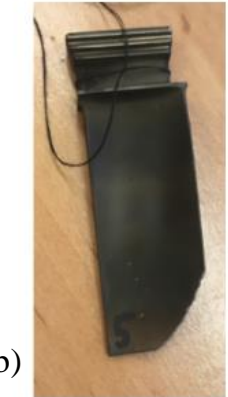

c)

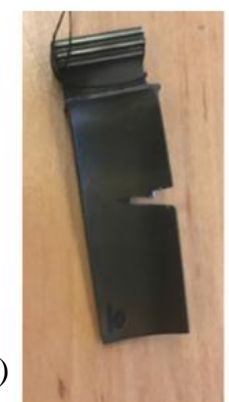

Fig. 1. Turbine blade: a) undamaged, b) damage simulating separation of the tip, c) damage simulating crack of the aerofoil part 


\subsection{The test stand}

The diagram of the test stand has been shown in Fig. 2 and the image of the stand in Fig. 3. The tested blades were hanging freely. The blade, when hit by the impact hammer (B\&K type 8206), moved slightly around its axis of rotation, which is why it was necessary to use two microphones (B\&K type 4189-A-021 1/2-inch free-field microphones with type 2671 preamplifier) set perpendicularly to each other on the same plane, in order to limit the errors of the response to the impact and increase the efficiency of the measurement.

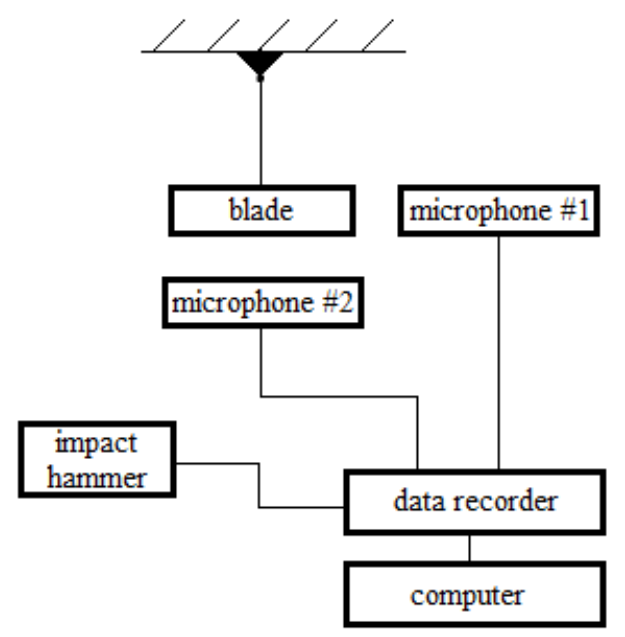

Fig. 2. Diagram of the test stand

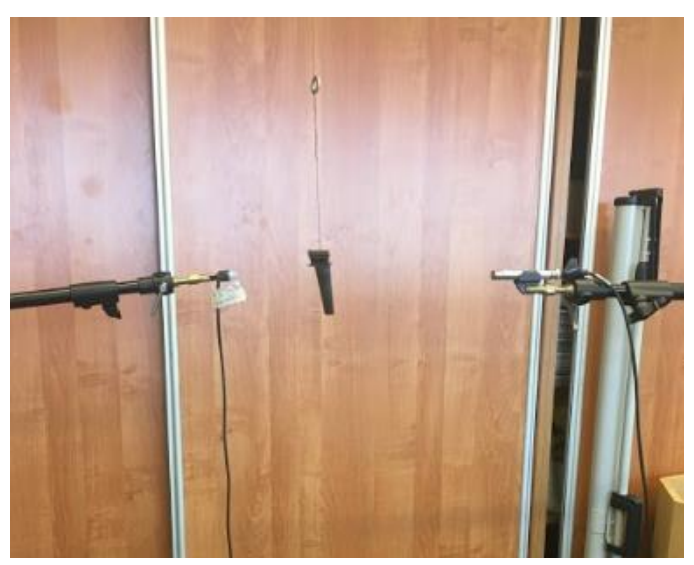

Fig. 3. Positioning of the microphones

All blades hung at the same distance from the microphones $(270 \mathrm{~mm})$ on the same height and were hit with the hammer on the same spots (on the blade face near the edge). The microphones and the impact hammer were connected directly to the measurement cassette (B\&K Input Module LAN-XI 51.2 kHz type 3050) and the data were recorded with the Pulse Time Data Recorder.

\subsection{Parameters of the signal analysis}

The BK Connect software used for the analysis and visualization of the results utilizes a FFT analysis converting the function of vibration from time to frequency. In order to obtain the interpretable results, it was necessary to determine the ratio of the output signal spectrum, i.e. vibration response of the blade to the impact of the hammer. This relation is mathematically described by the signalindependent descriptor referred to as the Frequency Response Function (FRF), defined by the formula:

$$
H(\omega)=\frac{X(\omega)}{F(\omega)}
$$

where: $X(\omega)$ - output signal in the domain of frequency, $F(\omega)$ - input signal in the domain of frequency. Linearity and constancy of the model was assumed [6].

Depending on the nature of the noise and distortions, during the measurement, a predefined estimator of the FRF analysis is applied to minimize the errors. For the case of the hammer impacts, the $\mathrm{H}_{1}$ estimator was applied for noises in the input signal [3,8], described with the formula:

$$
\mathrm{H}_{1}(\omega)=\frac{\mathrm{G}_{\mathrm{FX}}(\omega)}{\mathrm{G}_{\mathrm{FF}}(\omega)}
$$

where: $\mathrm{G}_{\mathrm{FX}}(\omega)$ - the cross spectrum, between the response and force, $G_{F F}(\omega)$ - the autospectrum of the force.

The signal conversion scheme in this analysis is presented in Fig. 4.

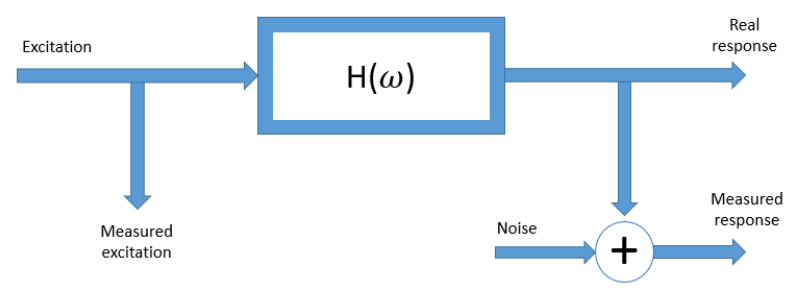

Fig. 4. Scheme for estimating the FRF function

The input parameters of the FFT analysis, selected to properly process the signal with sufficient accuracy have been shown in Table 1.

Table 1. Selected parameters of the FFT analysis

\begin{tabular}{|l|c|}
\hline Parameter name & Value \\
\hline Signal Type & transient \\
\hline Frequency Range & $25.6 \mathrm{kHz}$ \\
\hline Frequency Resolution & $32 \mathrm{~Hz}$ \\
\hline FFT Lines & 800 \\
\hline Average Domain & spectrum averaging \\
\hline Time Weighting & uniform \\
\hline Reference Signal & $\begin{array}{c}\text { impact hammer } \\
\text { excitation }\end{array}$ \\
\hline Minimum reference signal level & $50 \mathrm{~N}$ \\
\hline
\end{tabular}

The resolution of the spectrum and the accuracy of the FFT analysis when processing the signals were selected based on [9] for the conditions of the investigations and expected results, to make the interpretation as convenient as possible. Already at this stage, spectrum averaging of 4 impacts on each of the blades was performed.

\subsection{Results of analyses}

Throughout the tests, the authors obtained a total of 15 characteristics: 11 for potentially undamaged blades, 2 for the intentionally damaged blades and 2 comparative ones in order to determine the differences in the vibration spectrums.

Based on the characteristics, one may observe a relation between the values of the FRF function in the $y$-axis, ex- 
pressed in $\mathrm{Pa} / \mathrm{N}$ and the frequency of vibration in the $\mathrm{X}$-axis (in $\mathrm{kHz}$ ). They are a result of averaging (already at the stage of the FFT analysis) of the response from series 4 of the impacts for each blade. The amplitudes have a varied size because the FRF values are directly dependent on the impact force of the hammer that was not the same for all the measurements. 'Linear magnitude' visualization form was selected showing only the positive values of the spectrum in the linear scale. The analyses of the frequency spectrums of the responses received by both microphones were merged into a single spectrum. An example of the sound spectrum as a function of transmittance of the blade identified as undamaged based on a visual inspection has been shown in Fig. 5.

It was observed that the natural frequency, corresponding to the local amplitude maximums is similar for all 11 spectrums, though their general shapes and dominating frequencies vary.

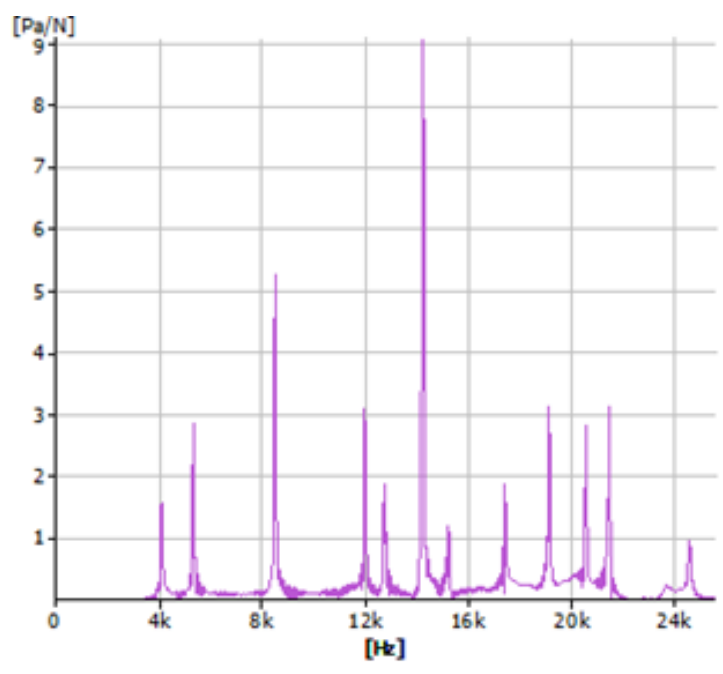

Fig. 5. Sound spectrum of the undamaged turbine blade no. 3

The comparative characteristics of the spectrum for the damaged blades no. 5 and 10 have been shown in Fig. 6 .
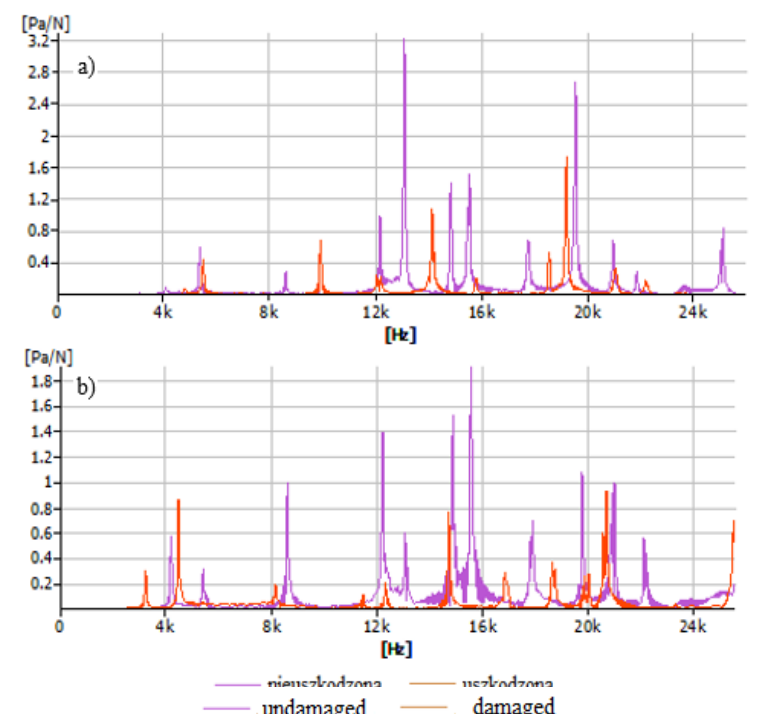

Fig. 6. Comparison of the sound amplitude spectrums: a) blade no. 5 before and after damage, b) blade no. 10 before and after damage
Already at the stage of visual comparison of the spectrums, it was observed how significantly the damage of the structure influenced the characteristics of the natural vibration of the blades. The frequency modes shifted and the amplitudes of the corresponding FRF values changed.

\subsection{Statistical analysis of the results}

The amplitude criterion was used to determine the resonance frequencies. It determines the natural frequency corresponding to the maximums of the amplitude in a given spectrum [12]. Upon comparing the natural frequency of the subsequent blades corresponding to the maximums of the FRF values, 12 main frequencies were observed and a sideband between mode XI and XII, appearing for the damaged blade no. 5 and the potentially undamaged blade no. 2. In the spectrum of blade no. 2, an additional band was found between modes VII and VIII.

For the statistical analysis, it was assumed that the investigated natural frequencies are a sample from the population of 84 blades of the turbine rotor; For the majority of the mode frequencies of the sample count $n=11$, for 5 of them $\mathrm{n}=10$, due to a lack of a given frequency in the spectrum of the blade. When creating the statistics, the natural frequencies of the damaged blades were not included similarly to the additional sidebands of the spectrum of the blade no. 2. The following statistical measures were applied: arithmetic average $\overline{\mathrm{x}}$, average square deviation $\mathrm{s}^{2}$, mean deviation $\mathrm{u}$, coefficient of variability $\mathrm{v}$, median $\mathrm{x}_{\mathrm{m}}$, range $r$ and center of range $c$. The results of the calculations of the statistical measures corresponding to the individual modes have been shown in Table 2 .

The values of the arithmetic average, median and center of the range are similar for most of the modes, but the average square deviation, range and coefficient of variability are increasingly higher for higher frequencies. This confirms an increasing variation of the resonance frequencies for a given mode while maintaining the expected average values.

In order to assess the confidence intervals, in which the expected value of the subsequent modes $\mu$ is found, given the small size of the sample and unknown standard deviation $\sigma$, the following model of the interval was used assuming a normal distribution of the population [2]:

$$
\mathrm{P}\left(\overline{\mathrm{X}}_{\mathrm{n}}+\mathrm{t}_{\frac{\alpha}{2}} * \frac{\mathrm{s}}{\sqrt{\mathrm{n}-1}}<\mu<\overline{\mathrm{x}}_{\mathrm{n}}+\mathrm{t}_{1-\frac{\alpha}{2}} * \frac{\mathrm{s}}{\sqrt{\mathrm{n}-1}}\right)=1-\alpha
$$

where: $\frac{t_{\alpha}}{2}, t_{1-\frac{\alpha}{2}}-$ quintiles of the Student distribution for $(n-1)$ degrees of freedom, $\alpha$ - coefficient of confidence, $\bar{x}_{n}$ - average value from the sample of count $n, \mu$ - expected value.

Initially, the confidence intervals were determined, within which the probability of falling of the expected frequency of a given mode in the intervals is $95 \%$ (coefficient $\alpha=0.05$ ), yet, not all natural frequencies obtained from the tracings fell in these intervals. This may have resulted from the assumption of a normal distribution, small size of the sample or non-representativeness of the sample (e.g. as a result of unexpected material flaws or fatigue). Upon changing of the confidence level to $99 \%$ (coefficient $\alpha=$ $=0.01$ ) the intervals extended and comprised the majority of the investigated frequencies. Table 3 presents the comparison of the natural frequencies of the damaged blades 
with the average values of the natural frequencies and the boundary values of the confidence intervals (at the confidence level of $\alpha=0.01$ ). The amber color represents those frequencies of the damaged blade modes that fall in the confidence intervals.

Table 2. Statistical measures for the frequencies of 12 modes

\begin{tabular}{|c|c|c|c|c|c|c|c|c|c|c|c|c|}
\hline Statistics & $\mathrm{f}_{1}[\mathrm{kHz}]$ & $\mathrm{f}_{2}[\mathrm{kHz}]$ & $\mathrm{f}_{3}[\mathrm{kHz}]$ & $\mathrm{f}_{4}[\mathrm{kHz}]$ & $\mathrm{f}_{5}[\mathrm{kHz}]$ & $\mathrm{f}_{6}[\mathrm{kHz}]$ & $\mathrm{f}_{7}[\mathrm{kHz}]$ & $\mathrm{f}_{8}[\mathrm{kHz}]$ & $\mathrm{f}_{9}[\mathrm{kHz}]$ & $\mathrm{f}_{10}[\mathrm{kHz}]$ & $\mathrm{f}_{11}[\mathrm{kHz}]$ & $\mathrm{f}_{12}[\mathrm{kHz}]$ \\
\hline$\overline{\mathrm{x}}$ & 4.148 & 5.405 & 8.547 & 12.134 & 12.806 & 14.575 & 15.375 & 17.501 & 19.340 & 20.672 & 21.647 & 24.807 \\
\hline $\mathrm{s}^{2}$ & 0.005 & 0.002 & 0.008 & 0.010 & 0.029 & 0.063 & 0.042 & 0.049 & 0.079 & 0.043 & 0.075 & 0.255 \\
\hline $\mathrm{u}$ & 0.063 & 0.033 & 0.078 & 0.076 & 0.141 & 0.194 & 0.182 & 0.184 & 0.257 & 0.169 & 0.199 & 0.383 \\
\hline $\mathrm{v}$ & $1.75 \%$ & $0.77 \%$ & $1.04 \%$ & $0.81 \%$ & $1.33 \%$ & $1.72 \%$ & $1.34 \%$ & $1.26 \%$ & $1.46 \%$ & $1.01 \%$ & $1.27 \%$ & $2.04 \%$ \\
\hline $\mathrm{x}_{\mathrm{m}}$ & 4.128 & 5.408 & 8.576 & 12.144 & 12.720 & 14.640 & 15.424 & 17.504 & 19.264 & 20.704 & 21.568 & 24.800 \\
\hline $\mathrm{r}$ & 0.224 & 0.096 & 0.288 & 0.256 & 0.480 & 0.640 & 0.672 & 0.768 & 0.864 & 0.640 & 0.832 & 1.664 \\
\hline $\mathrm{c}$ & 4.144 & 5.392 & 8.560 & 12.096 & 12.848 & 14.544 & 15.344 & 17.504 & 19.344 & 20.640 & 21.536 & 24.704 \\
\hline
\end{tabular}

Despite serious damage to the blade structure and a change in their rigidity, the frequency of mode IX of the spectrum of blade no. 5 and the frequencies of modes VI and $\mathrm{X}$ of the spectrum of blade no. 10 fall in the confidence intervals, hence, a separate analysis of these modes does not provide sufficiently reliable diagnostic information related to the technical condition of a component.

Even though the FRF values, corresponding to the frequencies dominating in the spectrums, are different for the subsequent blades, upon comparing of the modes with the highest amplitudes it was observed that the maximum amplitudes of the transmittance function for the investigated components most frequently fall in the interval $\mathrm{f}=12.806$ $17.501 \mathrm{kHz}$ (between mode $\mathrm{V}$ and VIII) deemed as midpositioned in the vibration spectrum.

\section{Interpretation of the results}

In the case of the turbine blades whose visual inspection did not reveal any damage, the impulse test allowed measuring the resonance frequencies in the amplitude spectrum of the FRF function and a statistical analysis of their values. The analysis also allowed the determination of the confidence intervals for the determined values of the frequencies. Locally, sudden surges of amplitudes confirming the phenomenon of resonance appeared in the majority of the spectrums 12 times for the following frequencies (the presented results are an arithmetic average with an estimate error for the standard confidence level of $95 \%$ ):

$$
\begin{aligned}
& -\mathrm{f}_{1}=(4.148 \pm 0.049) \mathrm{kHz} \\
& -\mathrm{f}_{2}=(5.405 \pm 0.030) \mathrm{kHz} \\
& -\mathrm{f}_{3}=(8.547 \pm 0.060) \mathrm{kHz} \\
& -\mathrm{f}_{4}=(12.134 \pm 0.070) \mathrm{kHz} \\
& -\mathrm{f}_{5}=(12.806 \pm 0.122) \mathrm{kHz} \\
& -\mathrm{f}_{6}=(14.575 \pm 0.179) \mathrm{kHz} \\
& -\mathrm{f}_{7}=(15.375 \pm 0.138) \mathrm{kHz} \\
& -\mathrm{f}_{8}=(17.501 \pm 0.149) \mathrm{kHz} \\
& -\mathrm{f}_{9}=(19.340 \pm 0.189) \mathrm{kHz} \\
& -\mathrm{f}_{10}=(20.672 \pm 0.140) \mathrm{kHz} \\
& -\mathrm{f}_{11}=(21.647 \pm 0.184) \mathrm{kHz} \\
& -\mathrm{f}_{12}=(24.807 \pm 0.361) \mathrm{kHz}
\end{aligned}
$$

The frequencies of the vibroacoustic response to the impact are in the range $\mathrm{f}=4-26 \mathrm{kHz}$ whereas the densification of the resonance frequencies falls in the range $\mathrm{f}=12-18$
$\mathrm{kHz}$. In addition, in the same range, the frequencies dominate in the entire spectrum. Such a composition of the spectrum components may indicate a similarity to a normal distribution.

In the spectrums of some of the blades less than 12 modes were read, which may indicate small structural changes, which resulted in a lack of a given natural frequency. The appearance of additional bands $\mathrm{f}_{7}$, and $\mathrm{f}_{11}$, in the spectrum of blade no. 2 most likely identifies microcracks that provide additional resonance [11].

It was observed that along the increase in the vibration frequency the spread of the results around the average value increased, which resulted in a wider confidence interval for the expected value and a greater estimate error. Particularly the frequency of mode XII significantly differed for each spectrum. This may be the consequence of the Doppler's effect distorting the measurement of the vibroacoustic response recorded by the microphones. The most 'unchanging' appear to be the first four modes, therefore their observations may be treated as the most reliable diagnostic information during the analysis of the spectrums for the assessment of the diagnostic condition.

The investigated deformation of the structure and the change in the rigidity of the blade following an intentional tear of the blade tip significantly modified the vibration spectrum of the component, thus changing the characteristic natural frequencies. This resulted in an increase in the majority of the natural frequency values and a decay of the mode from the center band as well as the final mode, which reduced the spectrum range. The highest FRF value, corresponding to the main dominating frequency falls in the middle of the second part of the spectrum range, only to make the resonance frequency amplitude drop rapidly. Therefore, the damaging of the right side of the blade (in relation to the point of impact) caused a left side asymmetry of the vibration spectrum.

Cutting the blade in the middle of its length caused a clear spread of the first (I-V mode) and second (VII-IX mode) part of the vibration spectrum, while maintaining the almost unchanged middle (VI mode) and final (XII mode) value of the natural frequency. In the case of such damage, the vibrations of both 'halves' of the blades have a mutual impact, thus augmenting the resonance (the dominating 
frequencies are clearly distinguished through their amplitude against the outstanding bands and fall in the beginning, middle and end of the spectrum range, while in the spec- trum of the same undamaged blade, the frequencies have a distribution similar to normal with the maximum amplitude for the center (VI mode).

Table 3. Comparison of the boundary values of the confidence interval and the average value of the natural frequency of the undamaged blades with the frequencies of the damaged blades modes

\begin{tabular}{|c|c|c|c|c|c|}
\hline \multirow{2}{*}{$\begin{array}{c}\text { Mode } \\
\text { frequency }\end{array}$} & \multicolumn{3}{|c|}{ Frequencies of the undamaged blades } & \multicolumn{2}{|c|}{ Frequencies of the damaged blades } \\
\hline & $\begin{array}{c}\text { Lower confidence } \\
\text { limit }\end{array}$ & $\begin{array}{c}\text { Mean } \\
\overline{\mathrm{x}}\end{array}$ & $\begin{array}{c}\text { Upper confidence } \\
\text { limit }\end{array}$ & Blade no. 5 damaged & Blade no. 10 damaged \\
\hline $\mathrm{f}_{1}[\mathrm{kHz}]$ & 4.079 & 4.148 & 4.218 & 4.768 & 3.232 \\
\hline $\mathrm{f}_{2}[\mathrm{kHz}]$ & 5.362 & 5.405 & 5.448 & 5.504 & 4.480 \\
\hline $\mathrm{f}_{3}[\mathrm{kHz}]$ & 8.462 & 8.547 & 8.632 & 9.920 & 8.160 \\
\hline $\mathrm{f}_{4}[\mathrm{kHz}]$ & 12.034 & 12.134 & 12.235 & 12.032 & 11.488 \\
\hline $\mathrm{f}_{5}[\mathrm{kHz}]$ & 12.631 & 12.806 & 12.981 & - & 12.320 \\
\hline $\mathrm{f}_{6}[\mathrm{kHz}]$ & 14.29 & 14.575 & 14.800 & 14.88 & 14.720 \\
\hline $\mathrm{f}_{7}[\mathrm{kHz}]$ & 15.178 & 15.375 & 15.571 & 15.808 & 16.864 \\
\hline $\mathrm{f}_{8}[\mathrm{kHz}]$ & 17.29 & 17.501 & 17.712 & 18.560 & 18.656 \\
\hline $\mathrm{f}_{9}[\mathrm{kHz}]$ & 19.071 & 19.340 & 19.609 & 19.200 & 20.032 \\
\hline $\mathrm{f}_{10}[\mathrm{kHz}]$ & 20.473 & 20.672 & 20.871 & 21.056 & 20.704 \\
\hline $\mathrm{f}_{11}[\mathrm{kHz}]$ & 21.385 & 21.408 & 21.91 & 22.208 & - \\
\hline $\mathrm{f}_{12}[\mathrm{kHz}]$ & 24.288 & 24.807 & 25.326 & - & 25.536 \\
\hline
\end{tabular}

\section{Conclusions}

Diagnostic methods utilize both the data coming from the vibroacoustic residual processes, generated by the engine and those contained in the response to controlled vibration impacts. The modal analysis allows observing the relation between the vibration impacts and the change in the natural frequency and determine the resonance characteristics for a specifically structurally determined blade. As a non-destructive method it may be used at the design as well as the overhaul stages of the engine life cycle.

The applied method of vibration analysis was an impulse test on a turbine blade (SO-3 engine) based on the assumptions of a modal analysis, yet, its results are limited to the interpretation of the vibration frequency spectrum obtained following the Fast Fourier Transform. Aside from the vibration frequency, the measured value was not the basic vibration parameter (e.g. acceleration) but a ratio of the vibroacoustic response to the force of the impact determined by the transmittance function referred to as FRF.

The performed investigations of the vibration characteristics of the turbine blades of an SO-3 jet engine have proven the effectiveness of the impulse test as a diagnostic method of the technical condition. An impact force and the measurement of the vibroacoustic response of the blades allowed the determination of the frequency signature with a certain confidence level for a given statistical sample.

The turbine blade of given own parameters has 12 main resonance frequencies in the range $4-26 \mathrm{kHz}$, whereas the dominating frequencies in the spectrum most often come from the range $12-18 \mathrm{kHz}$. The spread of values around the average in the sample was particularly high for higher natu- ral frequencies. The average, the median and the center of the spread were similar for all the modes. The coefficient of variability reached the lowest values for modes II and IV (below 1\%) and the highest values for modes XI and XII (above $2 \%$ ), which confirms a significant variation of the distribution in the end of the spectrum range and a lower certainty in its diagnostic use. Besides, lack of some of the modes in the spectrums or the existence of additional sidebands are deviations from the set standard that may indicate interior micro-cracks and deformations of the blade structure that is undetectable without specialized equipment.

The influence of mechanical damage of the aerofoil part of the blade dramatically changed the distribution of the modes in the spectrum and the amplitude values. Upon shifting the modes towards higher or lower frequencies one may identify the location and type of damage. When the tip of the blade is torn the distribution of the natural frequencies is asymmetrical, and for the crack along the central part of the blade, the first and the second part of the spectrum get separated, and the dominating ranges have an amplitude unproportionally high compared to the outstanding ones.

Such significant changes in the vibroacoustic response of a damaged component confirm the applicability of the impulse test for the diagnostic assessment of a technical object.

\section{Acknowledgements}

The presented results have been co-financed from the subsidies appropriated by the Ministry of Science and Higher Education - 0416/SBAD/0001.

\section{Nomenclature}

$F(\omega)$ input signal in the domain of frequency

FFT fast Fourier transform

FRF frequency response function
$\mathrm{G}_{\mathrm{FX}}(\omega)$ the cross spectrum

$\mathrm{G}_{\mathrm{FF}}(\omega)$ the autospectrum of the force

$X(\omega)$ output signal in the domain of frequency 


\section{Bibliography}

[1] BŁACHNIO, J., BOGDAN, M., ZASADA, J. Increased temperature impact on durability of gas turbine blades. Eksploatacja i Niezawodnosc - Maintenance and Reliability. 2017, 19, 48-53. https://doi.org/10.17531/ein.2017.1.7

[2] BOBROWSKI, D., MAĆKOWIAK-ŁYBACKA, K. Selected Statistical Inference Methods. Poznań University of Technology Publishing House, Poznań 2006 (in Polish).

[3] DØSSING, O. Structural testing, mechanical mobility measurements. Katalog Bruel \& Kjaer 1988.

[4] DŻYGADŁO, Z., ŁYŻWIŃSKI, M., OTYŚ, J. et al. Rotor assemblies of turbine engines. Transport and Communication Publishers. Warszawa 1982 (in Polish).

[5] GOLEWSKI, P. Thermo-mechanical loads on turbine engine blades with ceramic protective coatings. Doctoral Thesis. Lublin University of Technology. Lublin 2015. http://bc.pollub.pl/publication/12481 (in Polish).

[6] JACOBSEN, N.-J. Seminar and Workshop on Structural Dynamics. Poznan University of Technology Publishing House. Poznań 2018.

[7] LIPKA, J. Strength of Rotating Machinery. Scientific and Technical Publishing House. Warszawa 1967 (in Polish).

[8] MERKISZ, J., WALIGÓRSKI, M. Numerical method of vibroacoustic estimators analysis in a frequency domain for IC engine. Combustion Engines. 2013, 154(3), 25-33.

Julia Milewicz, BSc., Eng. - Faculty of Civil and

Transport Engineering, Poznan University of Technology.

e-mail:julia.milewicz@student.put.poznan.pl http://yadda.icm.edu.pl/yadda/element/bwmeta1.element.baz tech-1dc7a641-04c4-4100-b2f3-8b7185e08934

[9] MITCHELL, L.D. Improved methods for the FFT calculation of the frequency response function. Journal of Mechanical Design. 1982, 104, 277-279. https://doi.org/10.1115/1.3256336

[10] Engine description, no. 17.0.248. Transport Equipment Manufacturing Plant PZL-Rzeszów. 1977 (in Polish).

[11] WILK, A., MADEJ, H., LAZARZ, B. The application of time-frequency analysis of vibration for gears diagnostics. Scientific Journal of Silesian University of Technology. Series Transport. Katowice 2001, 42 (in Polish).

http://www.obrum.gliwice.pl/upload/downloads/spg/101/07 _WILK_MADEJ_LAZARZ.pdf

[12] WIŚNIEWSKI, W. Ground vibration tests of flying objects - methods and results analysis. Transactions of the Institute of Aviation. Warszawa 2010, 7 (in Polish).

http://yadda.icm.edu.pl/baztech/element/bwmeta1.element.b aztech-article-BSW4-0096-0015

[13] WITOŚ, M. On the modal analysis of a cracking compressor blade. Research Works of Air Force Institute of Technology. Warszawa 2008, 23, 5-20 (in Polish)

http://yadda.icm.edu.pl/baztech/element/bwmeta1.element.b aztech-article-BWM4-0022-0049

Daniel Mokrzan, BSc., Eng. - Faculty of Civil and

Transport Engineering, Poznan University of Technology.

e-mail:daniel.mokrzan@student.put.poznan.pl

Grzegorz M. Szymański, DSc., DEng., Prof. PUT

- Faculty of Civil and Transport Engineering, Poznan University of Technology.

e-mail: grzegorz.m.szymanski@put.poznan.pl 